\title{
ATTITUDE OF MANAGEMENT STUDENTS TOWARDS WHISTLEBLOWING: EVIDENCE FROM CROATIA
}

\section{Bogdanovic, M., Tyll, L.}

This study examines the attitude of management students towards whistleblowing in a sample of 121 master students of business ethics at the Faculty of Economics University in Split, Croatia. The three measurement instruments include whistleblowers' attitudes (3 items), whistleblowing attitudes ( 2 items) and potential types of whistleblowing reactions ( 8 items), i.e. external reactions (4 items) and internal reactions (4 items). The results of the study indicated a positive attitude toward whistleblowing and whistleblowers. The authors also found that female students exhibited more confidence in management and were more prone to whistleblowing than male students. Also, students with professional experience considered whistleblowing to be in the public interest more than students with no professional experience. The results may be of practical use to managers who can benefit from whistleblowing while keeping in mind that whistleblowing can't be avoided and that punishing whistleblowers seems to be a bad managerial practice.

Keywords: Whistleblowing; ethical climate; ethical culture; organization and management improvement; business ethics.

JEL Classification: M1, M5

\section{Introduction}

The term whistleblowing originates from the practice of English policemen who blew their whistle when they observed a crime. The blowing of a whistle alerted other law enforcement officers and the general public that a crime was being committed (Dasgupta and Tavakoli, 2010). In organizational life, the most commonly accepted definition of whistleblowing is "the disclosure by organization members (former or current) of illegal, immoral and illegitimate practices under the control of their employers to persons and organizations that may be able to effect action" (Near and Miceli, 1985).

Whistleblowing is for businesses, organizations and management an interesting but complex phenomenon that appears to be occurring with greater frequency throughout the world. In numerous examples, due to external whistleblowers' activity, the public get acquainted with ethical and legal abuses in business and governmental organizations. Whistleblowers teach about violation of law, misuse of public funds, falsifying documents, mismanagement, misuse of public facilities, questionable research activities, excessive spending, censorship (Soaken and Soaken, 1986), unsafe products, corruption, waste of resources (material, financial, human), or ecological misuse. From whistleblowers we learn about the "dark side" of business, organizations and management in numerous existing forms. The most common types of wrongdoing which can provoke whistleblower behavior are presented in table 1. 


\begin{tabular}{|l|l|}
\hline Category & Constituents \\
\hline Stealing & $\begin{array}{l}\text { Stealing of funds, stealing of property, accepting bribes/kickbacks, use of } \\
\text { an official position for personal benefit, unfair advantage to contractor, } \\
\text { and employee abuse of office }\end{array}$ \\
\hline Wasting & Wasting of organizational assets, wasting social benefits \\
\hline Mismanagement & $\begin{array}{l}\text { Management cover-up of poor performance and making false projections } \\
\text { of performance }\end{array}$ \\
\hline Safety problems & Unsafe or non-compliant products and unsafe working conditions \\
\hline Sexual harassment & $\begin{array}{l}\text { Unwelcome sexual advances/requests for sexual favors and verbal/ } \\
\text { physical contact of sexual nature }\end{array}$ \\
\hline Unfair discrimination & Discrimination based on race, sex, religion, etc. \\
\hline Legal violations & Violations of law, etc. \\
\hline
\end{tabular}

Source: Dasgupta and Ankit (2010).

The basic question in evaluating the whistleblowers activity is: "Are whistleblowers betrayers or heroes?" There are two opposite reasoning: whistleblowing can be seen as a negative or a positive activity (Tavakoli et al., 2003).

From the point of view of those who are absolutely loyal to governments, corporations and in general to the organizations which tend to hide exceeding, bypassing or disregarding of laws or standards, whistleblowers are betrayers. In some cultures, social norms say that it is disloyal to the organization and management to blow the whistle, and in contrary conformity and obedience to hierarchy is highly valued. From such a narrow perspective, the wrongdoer is in fact the whistleblower, not his management/ other employee who commits any kind of wrongdoing mentioned in Table 1. Such a cultural perspective considers a whistleblower as an "evil" because of his/her "dark motivation" resulting from either intention for revenge against his organization, or having some financial benefits from whistleblowing and perhaps reinstatement of employment (e.g. manipulation of some kind or blackmailing in order to achieve better organizational position). From the economic point of view, whistleblowing is an undesirable course of action because it could confound all the marketing and PR efforts and seriously damage the image of the organization (Tavakoli et al., 2003).

From the perspective of the second group of people who fully obey and respect the law and social norms, "whistleblowers are heroes". They are loyal to the organization (to its mission statements, values, goals, etc.) since they are ready to inform and fight against any deviation from the corporation's own statements and values. Although whistleblowing could be considered as a step against managers or employees, it should not be seen as an act of damaging the corporate image but as an act of courage and support of the organization in a broader perspective. No employee is bound to be loyal towards any individual or group within an organization who violates the mission, goals and values of the organization (Vandekerchove and Commers, 2004.). A whistleblower could be seen 
as an altruistic person with unselfish concerns about the well-being of others to avoid the wrongdoing which harms the interests of the organization, its consumers, co-workers and the society in general (Arnold and Ponemon, 1991; Vinten, 2000; Dasgupta and Ankit, 2010).

So from the business ethics point of view, we can conclude that whistleblowers are dominantly heroic individuals who, in spite of severe resistance of the organization, protest against misbehavior in the attempt to fix it. Internal and external whistleblowers have the potential to be teachers (chancellors) and direction-proposers in institutional and systemic changes. Although both laws (which prescribe what should not be done) and ethical codes (which prescribe that something that is incorrect should not even be considered) exist when they are violated, whistleblowers help to avoid and fix any socially inappropriate behavior.

Although whistleblowers can provoke unpleasantness in the short-term, they support the organizational ideals and better system from a long-term sustainable socio-economic perspective. This is appreciated by multiple multinational enterprises (MNEs). Some of them have established special departments where whistleblowers may share their reports. Others have established ethics codes, which encourage employees to contact the organization's legal counsel in case of any illegal or unethical activities. In fact, a study of international codes of conduct for MNEs indicates a substantial agreement on the moral duties of MNEs (Tavakoli et al., 2003). Positive attitudes towards whistleblowing may help to predict or explain whistleblowing behavior, and prevent greater organizational damages. Because of the risk they face, they should be awarded in the same manner as entrepreneurs are awarded for their business risk taking since they represent a cardinal factor of growth and development of organizations and social systems.

Statistics about whistleblowers suggest that they are well educated, dedicated to their job, and good and reliable employees. Many of them are individuals with high working performance who feel invited to report about wrong doing in organization according to their own moral (moral ideology), and in general they believe that they are expected to blow the whistle in case of any misbehavior (Ottensmeyer and McCarty, 1996, p. 424-434).

Although whistleblowers want to improve the working environment and organizational performance due to their own personal beliefs in good, they regularly experience retaliation and animosity from their supervisors, peers and colleagues (Soaken and Soaken, 1986). They are also usually exposed to psychological pressure in the form of job ostracism (Wu et al., 2012). Courage to tell the unpleasant truth is often dangerous, but in fact it helps to develop the organization in a positive way (Lučić, 2013). ${ }^{2}$

Organizations and management do not react properly when ignoring, lying or even maltreating whistleblowers. Organizational performance and respect of ethics can be improved only when we are aware of drawbacks and weaknesses in our team and its behavior. And in case we don't have any other measures to recognize any misbehavior, whistleblowers could be one of the solutions. It could be surprising that in spite of very

1 Today in organizational life, many moral ideologies exist; the most famous are: idealism, ralativism, machiavelianism, golden ethical rule, narcism, utilitaranism, cost-benefit analysis and altruism (cf. Chudziska-Czupala, 2013).

2 Paraphrased from the great Croatian writers Miroslav Krleža and Ivo Andrić (Nobel prize bearer) "Lie is a religion of master and slaves, the truth is religion of strong and free human beings.“ 
bad treatment of whistleblowers (e.g. repression and retaliation), only in the US there are several hundred thousand whistleblowers in all the spheres of organizational life (Ottensmeyer and McCarty, 1996, p. 427). So it is a real and frequent phenomenon which needs to be researched in detail.

In Croatia, there has not been any research about whistleblowing done, although reality shows that it is not a rare phenomenon. The practice in Croatia shows that whistleblowing and whistleblowers are, in reality, condemned; they are treated extremely badly although in many cases they pointed out criminal and unethical acts which could accelerate organizational and social development. One very real and current problem in Croatia is corruption and theft. On 28 October 2013, a bill concerning protection of denunciators of anomalies (i.e. whistleblowers protection) was introduced in Croatia. The intention of this bill was to discourage the management from revengeful behavior against denunciators of anomalies, change the "climate of fear", stimulate socially responsible behavior, change the negative perception of whistleblowers, narrow the space for corruption and make a contribution in building a more righteous society (suggestion of Dr. Dražen Gorjanski).

To which extent are whistleblowers important in illuminating criminal acts, e.g. corruption, we may see in the research about corruption. Due to whistleblowing activities, $43 \%$ of corruption was uncovered whilst due to the police investigations this figure was just about 2-3\%. Whistleblowers are also extremely efficient in drawing attention to very different anomalies. When informing about such anomalies, there are, on average, 20 other active individuals (potential but inactive whistleblowers) who will follow them. Thus, we may consider it as an evidence of an economic adequacy of whistleblowing in battle against corruption when $1 \$$ invested into this purpose (whistleblowers support) results in 8 yield (prevented damage) (Vecernji list, 2014).

There are many ways to understand why CEOs or supervisors in general do not accept or even sanction whistleblowers. Considering different power related frameworks, whistleblowing can be understood as a two-way process, where reporting represents an attempt to elevate the whistleblower's own internal power over a dominant coalition in the organization and thus singular or repeated negative and retaliatory actions can be experienced within the organization against such initiative (Bjørkelo, 2013).

To achieve a higher level of satisfaction of organizational and social interests, we pursued research on attitudes of the most propulsive population, i.e. Master students of management who may in the future restructure the social attitudes toward whistleblowing.

This paper deals with exploration of different attitudes toward whistleblowing among master students of management in Croatia, and according to the obtained results, we propose measures to create such an ethical climate which will make whistleblowing unnecessary. The research questions (problems) are defined as follows:

a) What is the actual attitude of students of management towards whistleblowers, whistleblowing, and their potential whistleblowers' reaction?

b) What are the differences in the students' attitude towards whistleblowing and whistleblowers, potential whistleblowers' reaction with regard to gender?

c) What are the differences in the students' attitude towards whistleblowing and whistleblowers, potential whistleblowers' reaction with regard to organizational membership? 


\section{Methodology}

The area of whistleblowing in Croatia, as well as in other transition economies, is underresearched. Our research was conducted among master students of management in the Faculty of Economics, University in Split. These students are supposed to become future professionals and leaders of different enterprises. By this research, one might forecast what could be the attitude toward whistleblowing in the future and whether whistleblowing has a potential to drive organizational changes and development.

\subsection{Measurement instruments}

To understand the status quo and provide conclusions about potential future attitudes toward whistleblowing, the authors used a questionnaire with 13 items divided into four areas of research interest:

1. Attitudes to whistleblowers - 3 items;

2. Attitudes to whistleblowing (ethical correctness) - 2 items;

3. Whistleblowers' reaction - outside the organization (external) - 4 items;

4. Whistleblowers' reaction - inside the organization (internal) - 4 items.

The questionnaire used a 5 degree Likert-type response format according to the following scores:

- To measure attitudes toward whistleblowers and whistleblowing, we used the following response scale: 1. I strongly disagree; 2 . I disagree; 3 . I do not agree nor disagree; 4. I agree; 5. I strongly agree.

- To measure the whistleblowers' reaction, we used the following response scale: 1. I will never act in such a way; 2. I will not act in such a way; 3 . I am not sure if I would act in such a way; 4 . I believe I would act in such a way; 5 . I am sure that I will act in such a way.

The attitude questionnaires described some ethical attitudes about whistleblowers and the whistleblowing phenomenon. The reaction questionnaire described reactions in the whistleblowing situations in terms of what would the interviewee react like (external and/or internal) if he had the intention to "blow into the whistle". The original questionnaire is provided in the appendix. The metric characteristics obtained on the Croatian student sample $(\mathrm{N}=121)$ are presented in table 2 .

Table 2 indicates that all variables have sufficient reliability. Variable "attitude to whistleblowers" has the lowest reliability (Alpha $=0.62$ ), which, however, can be seen as enough (DeVellis, 1991). ${ }^{3}$

For the variables: "attitude towards whistleblowing"; "total attitude to whistleblowers and whistleblowing"; "external whistleblowers reaction"; "internal whistleblowers reaction", "total reaction" and "total measurement scale" the reliability was from 0.74 to 0.83 , i.e. very good to excellent (DeVellis, 1991). Because the variable attitude to whistleblowers has small but acceptable reliability (Cronbach Alpha $=0.62$ ), the attitude to whistleblowing (Alpha $=0.83$ ) is more stable than attitude to whistleblowers (Alpha $=0.62$ ).

3 According DeVellis (1991) the Cronbach alpha reliability should be interpreded as follow:

$<0,60=$ not acceptable; $0,60-0,65=$ borderline (can be treated as acceptable); $0,65-0,70=$ acceptable;

$0,70-0,80=$ very good; $0.80-0.90=$ excelent; $>0.90=$ the scale should be shortened. 
Thus, interviewees are more consistent in their attitude toward whistleblowing as a phenomenon than in their attitude toward individuals who did the whistleblowing.

Table 2 | Basic psychometric norms achieved on Croatian sample for the key whistleblowing variables

\begin{tabular}{|l|c|c|c|}
\hline Variable name & Mean & $\begin{array}{c}\text { Standard } \\
\text { deviation }\end{array}$ & $\begin{array}{c}\text { Cronbach } \\
\text { alpha }\end{array}$ \\
\hline Attitude to whistleblowers (N=3 items) & 3.75 & 0.78 & 0.62 \\
\hline Attitude to whistleblowing (N=2 items) & 3.79 & 0.95 & 0.83 \\
\hline $\begin{array}{l}\text { Total attitude to whistlebowers and } \\
\text { whistleblowing (N=5 items) }\end{array}$ & 3.73 & 0.75 & 0.77 \\
\hline External whistleblowers' reaction (N=4 items) & 3.16 & 0.85 & 0.79 \\
\hline Internal whistleblowers' reaction (N=4 items) & 3.40 & 0.98 & 0.80 \\
\hline $\begin{array}{l}\text { Total (external and internal) whistleblower } \\
\text { reaction (N=8 items) }\end{array}$ & 3.28 & 0.69 & 0.74 \\
\hline Total scale (N=13 items) & 3.47 & 1.12 & 0.80 \\
\hline
\end{tabular}

Source: Authors

Table 3 presents the intercorrelations' matrix between items to show what items are overlapping (measure the same thing).

Table 3 | Intercorrelations between questionnaire items

\begin{tabular}{|c|c|c|c|c|c|c|c|c|c|c|c|c|c|}
\hline & $\mathbf{1}$ & $\mathbf{2}$ & $\mathbf{3}$ & $\mathbf{4}$ & $\mathbf{5}$ & $\mathbf{6}$ & $\mathbf{7}$ & $\mathbf{8}$ & $\mathbf{9}$ & $\mathbf{1 0}$ & $\mathbf{1 1}$ & $\mathbf{1 2}$ & $\mathbf{1 3}$ \\
\hline $\mathbf{1}$ & 1 & & & & & & & & & & & & \\
\hline $\mathbf{2}$ & .198 & 1 & & & & & & & & & & & \\
\hline $\mathbf{3}$ & .358 & .507 & 1 & & & & & & & & & & \\
\hline $\mathbf{4}$ & .243 & .459 & .431 & 1 & & & & & & & & & \\
\hline $\mathbf{5}$ & .265 & .414 & .443 & .706 & 1 & & & & & & & & \\
\hline $\mathbf{6}$ & .069 & .279 & .233 & .234 & .350 & 1 & & & & & & & \\
\hline $\mathbf{7}$ & .075 & .085 & .167 & .225 & .218 & .487 & 1 & & & & & & \\
\hline $\mathbf{8}$ & .186 & .206 & .243 & .340 & .368 & .534 & .340 & 1 & & & & & \\
\hline $\mathbf{9}$ & .104 & .161 & .147 & .279 & .410 & .550 & .398 & .558 & 1 & & & & \\
\hline $\mathbf{1 0}$ & .300 & .229 & .258 & .208 & .260 & .161 & .121 & .069 & .129 & 1 & & & \\
\hline $\mathbf{1 1}$ & .282 & .103 & -.012 & .194 & .249 & .126 & .057 & .054 & .186 & .571 & 1 & & \\
\hline $\mathbf{1 2}$ & .268 & .013 & .021 & .023 & .073 & .163 & .242 & .039 & .098 & .385 & .478 & 1 & \\
\hline $\mathbf{1 3}$ & .246 & -.034 & .085 & -.072 & -.050 & -.022 & .104 & -.071 & -.048 & .451 & .449 & .657 & 1 \\
\hline
\end{tabular}

Source: Authors 
The items of measurement showed relatively low intercorrelations so it can be considered that all the items are enough "pure" with tolerance in empirical overlap.

\subsection{Subjects}

The research was conducted in mid-December 2014 on the sample of 121 full time students of management during their first year of their master's degree studies (fourth year of integral study) at the Faculty of Economics, University in Split, Croatia. These were students attending the mandatory course of Business Ethics. From a total of 121 subjects, 84 were female and 37 were male, with an age spread from 22-48 years (22-25 years $85 \%$; 26-29 years $9.2 \%$ and $30-48$ years $5.8 \%$ ); 63 of them had a work experience, 58 had no work experience, 5 of them were married, 116 were single.

\subsection{Procedure}

Before the research, all the interviewees were instructed and got familiar with the type and the objective of the research, and they were asked for their approval to be included in this research. Only students who agreed to participate were included into our research. All the questionnaires were filled out anonymously within approximately five minutes. The data processing was conducted by SPSS statistical package.

\section{Results}

\subsection{General remarks on basic descriptive results for all the items}

As general overview of research items, the basic descriptive statistic is provided in table 4. There can be seen the answers about important whistleblower/whistleblowing questions in this research. The entire wording of each item is mentioned in the appendix.

Table 4 indicates that there is, in general, a positive attitude to whistleblowers (items $1,2,3, \mathrm{M}>3.50$ ) and also positive attitude to whistleblowing (items 4, 5, M>3.50). It is interesting that the dominant value (Mod) of item 4 ("Whistleblowing is a moral duty of every employee") is evaluated with the maximum grade $5(\mathrm{~N}=35$ students gave the grade 5 and $\mathrm{N}=34$ grade 4), so when there is a dominant opinion that to whistle into the organization is morally right, it increases the possibility of such a reaction. This indicates also the item 5 ("Whistleblowing is morally right") $\mathrm{M}=3.92$ and Mod 4 (actually also $\mathrm{N}=35$ interviewees give grade 5 , and $\mathrm{N}=47$ the grade 4). But of course what is "morally right" does not mean the same (consistent) behavior because it is mainly formed by means of awards and punishments (Pastuović, 1999). For managerial decisions, morality is very important (Chudziska-Czupala, 2013) but not the only influential factor, because there are also other important organizational structure/system and organizational culture aspects (Buble, 2006). So for an appropriate organizational behavior besides individual morality, it is very important to have an ethical climate/culture with ethical structures delivering substantial ethical difference.

The items which represent the whistleblowers' external reactions (items 6, 7, 8 and 9) are at a neutral grade $(M=3)$, also with $\mathrm{Mod}=3$. This indicates that interviewees, according to their previous experience of what may happen to the whistleblowers when they "blow the whistle" outside the organization, are not sure if this is an appropriate behavior, because experience says "Do not do it outside your home... Otherwise you will feel bad consequences!" 
Table 4 | Basic descriptive statistics for all the items ( $N=121)$

\begin{tabular}{|l|c|c|c|}
\hline Item & Mean & Std. Deviation & Mode \\
\hline one & 3.719 & 1.058 & 4 \\
\hline two & 3.818 & 1.024 & 4 \\
\hline three & 3.710 & 1.036 & 3 \\
\hline four & 3.669 & 1.128 & 5 \\
\hline five & 3.917 & .927 & 4 \\
\hline six & 3.181 & 1.048 & 3 \\
\hline seven & 3.338 & 1.004 & 3 \\
\hline eight & 3.016 & 1.080 & 3 \\
\hline nine & 3.082 & 1.201 & 3 \\
\hline ten & 3.669 & 1.199 & 4 \\
\hline eleven & 3.206 & 1.230 & 4 \\
\hline twelve & 3.322 & 1.259 & 4 \\
\hline thirteen & 3.388 & 1.286 & 3 \\
\hline
\end{tabular}

Source: Authors

The items, which represent the whistleblowers' internal reactions i.e. inside the organization (items, 10,11, 12,13) are at a higher value, dominantly $\mathrm{Mod}=4$, and the highest value is in the item 10 ("I will report to the person of trust in organization" $\mathrm{M}=3.67)$.

In general, we may note that the attitude toward whistleblowers and whistleblowing is more positive, than the potential reaction. So it can be concluded that the moral opinion, in case of whistleblowing, is not strong enough to pursue whistleblowing behavior, because of the Croatian and overall experience that whistleblowers are punished without exemption.

This conclusion confirmed also the slight correlation between total whistleblowing attitude and total whistleblowing reaction which is $\mathrm{r}=0.40$ and significant $\mathrm{p}<0.01$, so by means of attitude to whistleblowing it can only in small amount predict whistleblowing behavior.

\subsection{Attitude to whistleblowers, whistleblowing, and potential whistleblowers' reaction}

To evaluate the attitude of the current students of management toward whistleblowers, whistleblowing, and their potential whistleblowers' reaction, we first present the basic descriptive statistics for the whistleblowing variables in table 5. 
Table 5 | Basic descriptive statistics for key whistleblowing variables

\begin{tabular}{|l|c|c|c|}
\hline Variable & Mean & Mode & Std. Deviation \\
\hline 1. Total attitude & 3.766 & $3.40 \mathrm{a}$ & .747 \\
\hline 2. Total reaction & 3.275 & 3.50 & .692 \\
\hline 3. Whistleblowers' attitude & 3.749 & 4.00 & .784 \\
\hline 4. Whistleblowing attitude & 3.793 & 5.00 & .950 \\
\hline 5. Reaction external & 3.155 & 3.00 & .847 \\
\hline 6. Reaction internal & 3.396 & 3.00 & .983 \\
\hline
\end{tabular}

a. Multiple modes exist. The smallest value is shown

Note: 1. General attitude to whistleblowers and whistleblowing (items: 1, 2, 3, 4, 5); 2. General reaction to whistleblowing (items: 6, 7, 8, 9, 10, 11, 12, 13); 3. Attitude to whistleblowers (items 1, 2, 3); 4. Attitude to whistleblowing (items: 4, 5); 5. External reaction-outside the organization (items: 6, 7, 8, 9); 6. Internal reaction-inside the organization (items: 10, 11, 12, 13).

Source: Authors

The general attitude to the phenomenon of whistleblowing and whistleblowers is in general positive $(\mathrm{M}=3.77$; $\mathrm{s}=0.75)$ with multiple modes. There is also no evident difference between variables of whistleblowers' attitudes $(\mathrm{M}=3.75 ; \mathrm{s}=0.78)$ and whistleblowing attitudes $(\mathrm{M}=3.80 ; \mathrm{s}=0.95)$.

Total whistleblowing reaction on fictive unfairness is somewhat lower $(\mathrm{M}=3.28$, $\mathrm{s}=0.69$ ), although the most frequent value is 3.50 (17 from 121 answers); this is especially evident in comparison with total attitude ( $\mathrm{M}=3.77$ vs. $\mathrm{M}=3.28)$. External reaction is at lowest grade $(\mathrm{M}=3.16 ; \mathrm{s}=0.85)$, and the most frequent value is neutral answer $\mathrm{Mod}=3$ (24 from 121 answers) so there is less intention to "blow the whistle outside the organization", and "blowing into the whistle" inside the organization as well $(\mathrm{M}=3.40$; $\mathrm{s}=0.98$ ) and the most frequent value is neutral answer Mod=3 (14 from 121 answers).

The general remark is that the interviewees have a more positive attitude to whistleblowers/whistleblowing than it is their willingness to potentially "blow into the whistle", not even inside or outside the organizations which employ them. This may be a result of specific cultural socialization and experience that to "blow into the whistle" does not pay off, which is a well-known phenomenon of falsity in the modern society and organizational life.

\subsection{Answer on the second whistleblowing problem}

The second research question deals with the students' attitude to whistleblowing and their whistleblowers, potential whistleblowers' reaction with regard to gender. This problem is solved by the means of finding the statistical differences in all the variables by gender, by simple ANOVA. The results are presented in table 6 . 
Table 6 | Statistical differences in different whistleblowing attitudes with regard to gender (0-female; 1-male)/ANOVA

\begin{tabular}{|l|c|c|}
\hline Variable & F & p-value \\
\hline One & .013 & .911 \\
\hline Two & .274 & .602 \\
\hline Three & .104 & .747 \\
\hline Four & 1.189 & .278 \\
\hline Five & 1.160 & .284 \\
\hline Six & .105 & .747 \\
\hline Seven & .481 & .490 \\
\hline Eight & 1.052 & .307 \\
\hline Nine & .688 & .408 \\
\hline Ten & 1.241 & .267 \\
\hline Eleven & 2.959 & .088 \\
\hline Twelve & 8.367 & .005 \\
\hline Thirteen & 10.530 & .002 \\
\hline Whistleblowers' attitude & .102 & .750 \\
\hline Whistleblowing attitude & 1.378 & .243 \\
\hline Total attitude & .635 & .427 \\
\hline Reaction external & .859 & .356 \\
\hline Reaction internal & 8.280 & .005 \\
\hline Total reaction & 6.830 & .010 \\
\hline
\end{tabular}

Source: Authors

We found four statistical differences between female and male interviewees. These are:

a) A statistically significant difference between female and male interviewees was found in question 12 ("I will report to top management or to general management") where $\mathrm{F}=8.37 ; \mathrm{p}<0.01$. Female interviewees $(\mathrm{M}=3.54 ; \mathrm{s}=1.11)$ are more likely to report (whistle) to general management than male interviewees $(\mathrm{M}=2.84 ; \mathrm{s}=1.44)$.

b) A statistically significant difference between female and male interviewees was found in question 13 ("I will report firstly to my direct supervisor") where $F=10.53$; $\mathrm{p}<0.01$. Female interviewees $(\mathrm{M}=3.63 ; \mathrm{s}=1.16)$ are more likely to report (whistle) to the direct supervisors than male interviewees $(\mathrm{M}=2.84$; $\mathrm{s}=01.40)$.

c) A statistically significant difference between female and male interviewees was found in the variable of internal whistleblowing reaction where $F=7.55 ; \mathrm{p}<0.01$. Female interviewees $(\mathrm{M}=3.56 ; \mathrm{s}=0.80)$ are more likely to internally report (whistle 
on one of four ways stated in questionnaire, items $10,11,12,13)$ than male interviewees $(\mathrm{M}=3.02 ; \mathrm{s}=1.09)$.

d) A statistically significant difference between female and male interviewees was found in the variable of total whistleblowing reaction (external and internal) where $\mathrm{F}=6.83 ; \mathrm{p}=0.01)$. Also here female interviewees $(\mathrm{M}=3.38 ; \mathrm{s}=0.65)$ are more likely to have whistleblowing reaction (the both internal and external) than male interviewees $(\mathrm{M}=3.03 ; \mathrm{s}=0.59)$.

These differences between female and male interviewees show that female interviewees have more trust/confidence in management (the both i.e. highest and the first management level) than male interviewees, which could be possibly explained by cultural factors. In particular, in Splitsko-Dalmatinska County of Republic Croatia, it is still expected that male employees must earn enough to support their families and wives, so there are greater social consequences of whistleblowing in perceptions of male interviewees then by the female ones. So, in this context and according to such an upbringing, female interviewees could be "braver" than male interviewees because it could be perceived not that badly if women get fired or they have maltreatment in their work compared to their male peers. This could also be the explanation for greater propensity to internal "blow the whistle" by female interviewees.

\subsection{Answer on the third whistleblowing problem}

The third research problem was to test the differences in the students' attitude toward whistleblowing and whistleblowers, potential whistleblowers' reaction with regard to organizational membership. This problem is also solved by the means of finding the statistical differences in all the variables by organizational membership, by simple ANOVA. The results are presented in the table 7.

We found only two statistically significant differences and one borderline $(p=0.067)$ with regard to organizational membership. These are:

a) A statistically significant difference between interviewees who were organizational members and those who were not was found in question 3 ("Whistleblowers are good for public interest") where $F=5.60 ; p<0.05$. Organizational interviewees $(M=3.94$; $\mathrm{s}=0.96$ ) were more likely to think that whistleblowing is good for society compared to no-work experience interviewees $(\mathrm{M}=3.49$; $\mathrm{s}=1.08)$. So work experience makes the difference in perception of usefulness of whistleblowing for social welfare.

b) A statistically significant difference between the interviewees who were organizational members and those who were not was found in question 7 ("I will report to the authority outside the organization") where $F=5.45 ; \mathrm{p}<0.05$. Organizational interviewees $(\mathrm{M}=3.54 ; \mathrm{s}=1.00)$ were more likely to whistle outside the organization compared to no-work experience interviewees $(\mathrm{M}=3.12 ; \mathrm{s}=0.97)$.

c) A borderline statistically significant difference $(\mathrm{F}=3.42 ; \mathrm{p}=0.067)$ between interviewees who were organizational members and those who were not was found in question 6 ("I will use the information channels outside the organization"). Organizational interviewees $(\mathrm{M}=3.35 ; \mathrm{s}=1.12)$ were more likely to whistle from informational channels outside the organization compared to no-work experience interviewees $(\mathrm{M}=3.00 ; \mathrm{s}=0.94)$. 
Table 7 | Statistical differences in different whistleblowing attitudes with regard to organizational membership (0-No; 1-Yes)/ANOVA

\begin{tabular}{|c|c|c|}
\hline Variable & $\mathbf{F}$ & p-value \\
\hline One & .049 & .825 \\
\hline Two & 2.863 & .093 \\
\hline Three & 5.598 & .020 \\
\hline Four & .206 & .650 \\
\hline Five & 2.017 & .158 \\
\hline Six & 3.415 & .067 \\
\hline Seven & 5.448 & .021 \\
\hline Eight & .031 & .862 \\
\hline Nine & .111 & .740 \\
\hline Ten & 1.414 & .237 \\
\hline Eleven & 1.077 & .302 \\
\hline Twelve & 1.115 & .293 \\
\hline Thirteen & .398 & .529 \\
\hline $\begin{array}{l}\text { Whistleblowers' } \\
\text { attitude }\end{array}$ & 2.774 & .098 \\
\hline $\begin{array}{l}\text { Whistleblowing } \\
\text { attitude }\end{array}$ & .922 & .339 \\
\hline Total attitude & 2.368 & .126 \\
\hline Reaction external & 1.149 & .286 \\
\hline Reaction internal & .256 & .614 \\
\hline Total reaction & .086 & .769 \\
\hline
\end{tabular}

Source: Authors

From these differences we can conclude that organizational membership makes the interviewee more aware about the usefulness of whistleblowing, and also prone to use external informational sources to do whistleblowing. Thus, the organizational experience is one of the most important socializing factor in understanding the whistleblowing, and understanding why is the external whistle sometimes used instead of the internal one. 


\section{Discussion}

What can managers do to benefit from whistleblowing or how to manage it? The only good answer is to create such an ethical climate and culture where whistleblowing becomes unnecessary and where it is also beneficial for the organization. Any preventive actions are the best ones, but of course there should be also responsive (reaction) activities in managing the whistleblowing phenomenon. A short review of ways to manage whistleblowing is presented in table 8 .

Table 8 | Ways to manage whistleblowing in organizations

\begin{tabular}{|l|l|}
\hline Preventive Actions & Responsive Actions \\
\hline $\begin{array}{l}\text { Consider employee complaints } \\
\text { seriously and take action }\end{array}$ & Correct situations that are subject of whistleblowing \\
\hline $\begin{array}{l}\text { Establish an in-house complaint } \\
\text { process }\end{array}$ & Investigate claims and respond quickly \\
\hline $\begin{array}{l}\text { Lobby for comprehensive laws } \\
\text { governing whistleblowing }\end{array}$ & Train managers and employees to respond effectively \\
\hline $\begin{array}{l}\text { Monitor legislative actions and } \\
\text { anticipate changes }\end{array}$ & Punish wrongdoing appropriately \\
\hline $\begin{array}{l}\text { Communicate policies and } \\
\text { penalties to all employees }\end{array}$ & $\begin{array}{l}\text { Encourage use of alternative communication and resolution } \\
\text { mechanisms }\end{array}$ \\
\hline $\begin{array}{l}\text { Educate managers concerning } \\
\text { their role }\end{array}$ & Establish a supportive organizational culture \\
\hline Reward ethical behavior & Prescribe roles \\
\hline $\begin{array}{l}\text { Develop policies and codes of } \\
\text { ethics }\end{array}$ & Set up ombudsman or complaint handlers \\
\hline
\end{tabular}

Source: Paul and Townsend (1996); Dasgupta and Ankit (2010).

Because whistleblowers detect organizational problems in the early stage (similar to a canary in a mine which alarms where there are dangerous gases), every organization which pays attention to its reputation should force itself to solve the problem (which is the cause/matter of whistleblowing).

The typical management reaction is often counterproductive: management reacts vengefully at the first sign of whistleblowing, they do not think that it is the best solution to solve the problem before it escalates, they start to blaspheme and attack the whistleblower who activates the alarm. Management often treats the whistleblower as an individual who is mentally disordered, who wants to attract attention, who is undesirable for the organization and who should be dismissed soon. This course of action used by management to solve the deeper problem of misbehavior within the organization actually makes the problem more serious, with an impact also on an external society.

The existence of external whistleblowing is, in a certain manner, an organizational and managerial fault, which may have serious consequences for the whole organization 
and its image. The only approach used by management is to create such an internal environment and corporate culture which prevents any misbehavior. In case of any eventual wrong doing, whistleblowing should be considered as a warning alarm which has to be taken into serious consideration and it is used to ignite desirable courses of actions to fix the problem and restore the intra organizational climate complying with ethical standards. To detect the undesired wrong organizational behavior, we may ask the following key questions (Ottensmeyer and McCharty, 1996, p. 431):

- What kind of an organization are we?

- What are our values and behavior standards?

- What are our moral obligations?

- What costs and benefits are linked with achieving our values and standards?

- What do we do, to assure achieving our goals while keeping with our values and standards?

By answering these questions, management could clarify for itself what could be considered as wrong doing and thus specify potential problematic areas, e.g. agency issues, mismanagement etc. and make the organizational culture more resistant against any misbehavior. In other words, the management should start with a change of corporate culture which supports well doing instead of creating an environment with power as a key value and management tool. Changing the corporate culture requires changes in leadership structure in every single area of an organizational life. The power should be under the whistleblower's control. Whistleblowers should be provided with such a position, status and role which enable them to articulate any organizational problems, whatever they are and whoever caused them. Only by resolving organizational conflicts is it possible to improve human relationships, psychosocial working conditions and reduce whistleblowing as a target level.

There are these following elementary questions which may help management using organizational whistleblowing and whistleblowers as a development factor:

- Which activities in an organization are considered as wrong?

- Which activities in an organization are desirable?

- Who should be contacted by employees in case of any realized bad/wrong doing? Is that the direct supervisor or a manager on a higher level, HR department, organizational lawyer or anybody else?

Everybody within the organization should be certain about which activities are considered as wrong and what should be done when something like that occurs. If there is introduced and working such a system within an organization, then there is a potential for a self-correction. Thus, the company may be prevented from any external negative publicity or perception caused by any unpleasant incidence within the organization. From the management perspective, it is also important to create a sufficient level of trust between the organization, management and employees who may be certain that any problem or complain once validated would be solved or at least discussed.

Whistleblowers represent a dilemma for most managers, and often they are perceived as a threat. In the era when employees are expected to show greater job involvement/ 
engagement, it is important to see that whistleblowers are a valuable element of internal organizational self-control. If they are treated as engaged employees who can secure valuable information and solutions for managerial problems, they could improve their organization and management.

\section{Conclusion}

The phenomenon of whistleblowing and whistleblowers represents not only a managerial problem, but also a valuable driver in achieving better organizations' performance and better society in terms of better managerial decisions and strategy. The purpose of this paper was to measure the attitude and potential reaction to whistleblowing in the future by management executive population in Croatia, and to give some managerial suggestions on how to benefit from them.

The general attitude toward the phenomenon of whistleblowing and whistleblowers was, in general, positive. Total whistleblowing reactions on fictive unfairness were somewhat lower. External potential of whistleblowing reaction was at lowest grade and potential of "blowing into the whistle" inside the organization was also low. In general, we may conclude that the attitude to whistleblowers and whistleblowing is more positive than the potential reaction. Moral opinion about whistleblowing/whistleblowers was slightly but significantly connected with potential whistleblowing reaction. This could be expected because attitude to whistleblowing/whistleblowers is not big enough to produce whistleblowing behavior.

Statistically significant differences between female and male interviewees show that female interviewees have more trust/confidence in management (the both i.e. highest and the first management level), and they are statistically more prone to internal and total whistleblowing than male interviewees, which can be possibly explained by cultural factors.

Statistically significant differences between interviewees who have any working experience and those who have not, were found in moral attitude "Whistleblowing is a good thing for public interest" and potential external reaction by using information channels outside the organization. These results showed that organizational membership is a variable which considers whistleblowing as a moral act beneficial to the society, and social group with greater affinity to use external whistleblowing, more than those without any working experience.

This research showed that whistleblowing cannot be totally avoided, especially because of positive attitude to whistleblowing/whistleblowers of future managerial population. The present management methods of punishing whistleblowers to avoid whistleblowing are quite ineffective (because of wasting valuable resources). There is a much better strategy to use them and thus make organizations and management better. This can be made by creating such ethical climate and culture where whistleblowing becomes unnecessary. Namely, if whistleblowers are treated as engaged employees who can secure valuable information and solutions for managerial problems, they can really improve their organizations and management as well (cf. Seijts and Crim, 2006). So organizations can make profit from the fact that the most of the whistleblowers are prone to be actively engaged in fixing wrong doing, and so to develop and make more profit for their employers. 


\section{References}

Bjørkelo, B. (2013). Workplace bullying after whistleblowing: Future research and implications. Journal of Managerial Psychology, 28(3), 306-323.

Bogdanović, M. (2015). Dark side of business and management in function of economic (un) development, 4th International Scientific Symposium Economy of Eastern Croatia - Vision and Growth, Croatia, Osijek, 21 st - 23rd May 2015., p. 248-258.

Bogdanović, M. (2014). Deviant management values (Dark Triad) by Croatian management students. 7th International Conference on the School of Economics and Business in Sarajevo, Sarajevo 13th-14th October 2014., Bosnia and Herzegovina, Conference Proceedings, p. 226-242.

Buble, M. (2006). Management, Split: Ekonomski fakultet u Splitu.

Chudziska-Czupala, A. (2013). Ethical Ideology as a Predictor of Ethical Decision Making, The International Journal of Management and Business, 4(1), 82-104.

Dasgupta, S., \& Ankit, K. (2010). Whistleblowing: A survey of Literature. The IUP Journal of Corporate Governance, 9(4).

DeVellis, R. F. (1991). Scale development. Newbury Park, N. J.: Sage Publications.

Lučić, M. (2013). Istina je najvažnija: Intervju s Jackom Hawleyem. [Truth is the most important: Interview with Jack Hawley], qLife, 5(2), 45-58.

Near, J. P., \& Miceli, M. (1985). Organizational Dissidence: The Case of Whistleblowing, Journal of Business Ethics, 4(1), 1-16.

Ottensmeyer, E. J., \& McCarthy, G.D. (1996). Ethics in the Workplace. International Edition (New York... Toronto): McGraw-Hill Companies, Inc.

Pastuović, N. (1999). Edukologija [Educology], Zagreb: Znamen.

Seijts, G. H., \& Crim, D. (2006). What engages employees the most or, The Ten C's of employee engagement. Ivey Business Journal: Improving the Practice of Management, March/April 2006, pp. 1-5.

Tavakoli, A.A., Keenan, J. P., \& Crnjak-Karanović, B. (2003). Culture and Whistleblowing: An Empirical Study of Croatian and United States Managers Utilizing Hofstede`s Cultural Dimensions, Journal of Business Ethics, (March), 43(1-2): 49-64.

Vandekerchove W., \& Commers, M.S.R. (2004). Whistleblowing and Rational Loyalty, Journal of Business Ethics, 53(1-2): 225-233.

Wu, L.-Z., Yim, F. H.-k., Kwan, H. K. \& Zhang, X. (2012). Coping with Workplace Ostracizm. The Role of Ingratiation and Political Skill in Employee Psychological Distress, Journal of Management Studies, 49(1), 177-199.

Vecernji list (2014). Zviždaču nagrada 10\% od iznosa štete koju je spriječio [online]. Retrieved February 20, 2016 from http://www.vecernji.hr/hrvatska/ zvizdacu-nagrada-10-od-iznosa-stete-koju-je-sprijecio-920337. 


\section{APPENDIX}

\section{Total - 13 items}

\section{Attitudes towards whistleblowers}

1. Whistleblowers prevent greater damage to the organization.

2. Whistleblowers are the corruption control.

3. Whistleblowers are good for public interest.

\section{Attitudes towards whistleblowing (ethical correctness)}

4. To blow the whistle is the moral duty of every employee.

5. To blow the whistle is morally correct.

\section{Whistleblowers' reaction - outside the organization (external)}

6. I will use the information channels outside the organization.

7. I will report to the authority outside the organization.

8. I will report to NGOs (non-governmental organizations).

9. I will report to public using mass media.

\section{Whistleblowers' reaction - inside the organization (internal)}

10. I will report the person of my trust in the organization.

11. I will use internal organizational e-mail to report.

12. I will report to the top management or general manager.

13. I will report to my direct supervisor.

\section{Authors}

\section{doc. dr. Mario Bogdanovic}

Senior research associate

University of Split

Faculty of Economics

Management Department

Cvite Fiskovica 5

21.000 Split, Republic Croatia

mbogdan2011@gmail.com

\section{Ladislav Tyll, Ph.D.}

University of Economics, Prague

Faculty of Business Administration

Department of Strategy

nam. W. Churchilla 4

13067 Prague 3, Czech Republic

ladislav.tyll@vse.cz 